RESEARCH REPORT

\title{
Work related stressful life events and the risk of myocardial infarction. Case-control and case-crossover analyses within the Stockholm heart epidemiology programme (SHEEP)
}

\author{
Jette Möller, Töres Theorell, Ulf de Faire, Anders Ahlbom, Johan Hallqvist
}

J Epidemiol Community Health 2005;59:23-30. doi: 10.1136/jech.2003.019349

See end of article for authors' affiliations

Correspondence to: Mrs J Möller, Karolinska Institutet, Department of Public Health Sciences, Division of Social Medicine, Norrbacka, SE17176 Stockholm, Sweden; jette.moller@phs. ki.se

Accepted for publication 20 April 2004
Study objectives: Recent changes in labour market conditions and in the organisation of work in developed societies have increased exposure to work related stress. The question is whether this also implies an increased risk of myocardial infarction, either through the triggering effect of acute stress, or through accumulation of stress over several months.

Design: A case-control and a case-crossover study design was applied.

Setting: The Stockholm heart epidemiology programme (SHEEP), in Stockholm County during 1992 to 1994.

Participants: Patients with a first episode of non-fatal acute myocardial infarction, a total of 1381 men and women, responded to questionnaires and participated in interviews and health examinations.

Main results: The case-crossover analysis showed triggering effects of sudden, short term situations of increased work load or work competition. Having "had a high pressure deadline at work" entailed a sixfold increase in risk of myocardial infarction (OR=6.095\% $\mathrm{Cl}(1.8$ to 20.4$))$ during the next 24 hours. The importance of work related life events as risk factors for myocardial infarction was supported by the case-control analysis. However, no support was found for the hypothesis that an accumulation of stressful life events over a period of 12 months increases the risk of myocardial infarction.

Conclusion: Specific work related stressful life events seem to be potential triggers of the onset of myocardial infarction.
$\mathrm{R}$ esearch stimulated by the development of the casecrossover design has identified several potential triggers of myocardial infarction in recent years. Studies have shown triggering effects of peak exertion, ${ }^{1-3}$ episodes of intense anger, ${ }^{45}$ sexual activity, ${ }^{67}$ use of cocaine and marijuana, ${ }^{89}$ and bereavement. ${ }^{10}$ Haemodynamic stress in the coronary arteries and rupture of an atherosclerotic plaque, with consequent thrombosis, are considered to be the physiological mechanisms behind such associations. ${ }^{11}{ }^{12}$ Mental stress, especially negative emotional stress, has also been found to trigger episodes of silent myocardial ischaemia in a casecrossover study. ${ }^{13}$

Earlier case reports indicate that emotionally upsetting events occasionally precede the onset of myocardial infarction. ${ }^{14-18}$ Studies of war and natural catastrophes, such as earthquakes, have shown increased incidence of myocardial infarctions and related hospital admissions during and shortly after the time of the event. ${ }^{19-25}$ Incidence rates soon returned to expected levels, suggesting that the effects were fairly transient. Hence, it seems possible that stressful life events are involved in the process of myocardial infarction, perhaps acting late in the causal chain, namely as triggers.

Current changes in labour market conditions and work organisations, entailing increased competition and work load and less job security, have increased the importance of the work environment as a source of potentially harmful stress reactions, ${ }^{26}$ but so far no case-crossover study has been published that analyses whether work related life events trigger coronary heart disease.

The trigger mechanism assumes very short induction times, mostly in the range of less than an hour and up to a few days after exposure to a single event. An earlier hypothesis, proposed by Holmes and Rahe in the 1960s, suggested that it is the accumulation of stressful life events over a period of several months that increases stress, and thereby vulnerability to developing illness. The authors presented what they called a social readjustment rating scale (SRRS), which measures not only the quantity and types of life events in the accumulation process but also the magnitude of their objective stressful influences. ${ }^{27-29}$ Findings regarding accumulation of stress attributable to life events, as measured by the SRRS or other scales, ${ }^{30-32}$ in relation to the risk of cardiovascular disease are not unequivocal. ${ }^{33}$ Some studies ${ }^{34-39}$ support a relation between life events and cardiovascular disease, but others do not. ${ }^{40-44}$

Only a few studies have analysed the effects of life events within the framework of short induction periods, ${ }^{35}$ which makes it difficult to know whether at least some of the observed accumulation effect is attributable to triggering.

The aim of this study is to analyse the association between work related stressful life events and myocardial infarction, and-in particular-to test whether there is support for a trigger mechanism with a very short induction period or a mechanism involving the accumulation of stress over a longer period.

In a case-control study we first explored whether specific single life events increase the risk of myocardial infarction, and the extent to which any such excess risk is determined by the perceived significance of the event. We then performed a case-crossover study to explore whether work related life events may act as triggers of myocardial infarction with an induction period of one week or less. Finally, we analysed whether the risk of myocardial infarction is associated with an accumulation of life events over 12 months, as measured

Abbreviations: SHEEP, Stockholm heart epidemiology programme; SRRS, social readjustment rating scale 
Table 1 Characteristics of the SHEEP and onset study populations (\%)

\begin{tabular}{|c|c|c|c|c|c|c|}
\hline & \multicolumn{4}{|l|}{ SHEEP study } & \multirow{2}{*}{\multicolumn{2}{|c|}{ Onset study }} \\
\hline & \multicolumn{2}{|l|}{ Referents } & \multicolumn{2}{|l|}{ Cases } & & \\
\hline & Male $n=1148$ & Female $n=549$ & Male $n=968$ & Female $n=413$ & Male $n=507$ & Female $n=153$ \\
\hline Mean age & 58.6 & 61.8 & 58.5 & 61.6 & 59.2 & 62.1 \\
\hline \multicolumn{7}{|l|}{ Smoking } \\
\hline Current smoker & 33.9 & 23.7 & 28.6 & 15.5 & 31.4 & 19.3 \\
\hline Ex-smoker* & 31.2 & 26.1 & 50.8 & 51.8 & 47.3 & 45.0 \\
\hline Physical inactive $†$ & 33.0 & 40.8 & 43.2 & 55.6 & 37.6 & 63.0 \\
\hline Hypertension $\ddagger$ & 27.9 & 29.5 & 32.6 & 40.7 & 28.0 & 42.4 \\
\hline Diabetes & 5.5 & 3.6 & 12.5 & 17.2 & 12.6 & 17.4 \\
\hline Overweight§ & 29.7 & 33.2 & 43.4 & 45.3 & 43.6 & 42.4 \\
\hline \multicolumn{7}{|l|}{ Socioeconomic status } \\
\hline Manual worker & 22.4 & 28.1 & 31.7 & 34.1 & 23.5 & 29.4 \\
\hline Non-manual worker, low grade & 12.5 & 32.6 & 11.6 & 30.8 & 11.0 & 26.8 \\
\hline Non-manual worker, middle and high grade & 50.9 & 28.1 & 42.0 & 20.4 & 43.6 & 19.0 \\
\hline Self employed & 12.8 & 4.9 & 12.7 & 5.3 & 11.4 & 3.9 \\
\hline Others & 1.3 & 6.4 & 2.0 & 9.4 & $10.5^{\star *}$ & $20.9^{* *}$ \\
\hline \multicolumn{7}{|l|}{ Number of life events past 12 months } \\
\hline 0 & 28.5 & 29.1 & 29.3 & 28.6 & 26.9 & 25.9 \\
\hline 1 & 29.4 & 33.0 & 28.2 & 28.3 & 29.1 & 30.2 \\
\hline 2 & 19.7 & 19.3 & 18.6 & 19.9 & 20.4 & 25.2 \\
\hline 3 & 11.9 & 10.2 & 12.5 & 11.1 & 12.9 & 10.1 \\
\hline 4 & 5.5 & 4.7 & 5.5 & 8.5 & 5.5 & 5.8 \\
\hline 5 & 2.8 & 2.4 & 3.3 & 1.7 & 3.3 & 2.1 \\
\hline 6 & 1.7 & 0.7 & 1.8 & 1.5 & 0.7 & 0.7 \\
\hline 7 & 0.3 & 0.4 & 0.4 & 0.5 & 0.2 & 0 \\
\hline 8 & 0.1 & 0.2 & 0.2 & 0 & 0.2 & 0 \\
\hline$\geqslant 9$ & 0.2 & 0 & 0.2 & 0 & 0 & 0 \\
\hline Missing (n) & 1 & 0 & 2 & 2 & 50 & 14 \\
\hline \multicolumn{7}{|l|}{ SRRS points } \\
\hline 0 & 28.4 & 28.9 & 29.2 & 28.0 & 26.7 & 25.2 \\
\hline $1-36$ & 17.2 & 17.7 & 16.3 & 14.9 & 15.6 & 16.0 \\
\hline $37-78$ & 28.4 & 31.8 & 28.3 & 29.8 & 30.1 & 35.1 \\
\hline$\geqslant 79$ & 26.1 & 21.6 & 26.2 & 27.3 & 27.6 & 23.7 \\
\hline Missing (n) & 52 & 34 & 47 & 24 & 72 & 22 \\
\hline Impaired economic situation & 21.0 & 24.5 & 21.3 & 23.7 & 20.4 & 21.6 \\
\hline Conflict at work & 13.2 & 10.0 & 20.3 & 14.8 & 20.3 & 14.8 \\
\hline Change of workplace & 10.5 & 4.7 & 9.8 & 5.7 & 10.1 & 6.0 \\
\hline Decreased responsibilities at work & 9.6 & 4.6 & 10.2 & 2.5 & 8.4 & 2.2 \\
\hline Increased responsibilities at work & 15.5 & 12.3 & 16.3 & 12.9 & 16.1 & 13.5 \\
\hline
\end{tabular}

both by total number of events and by weighted accumulation according to the SRRS. ${ }^{27}$

\section{METHODS}

\section{The case-control study}

The Stockholm heart epidemiology programme (SHEEP) is a population based case-control study of first events of acute myocardial infarction, both fatal and non-fatal. The study base included all Swedish citizens 45 to 70 years old, living in Stockholm County and with no earlier diagnosed myocardial infarction. Male cases were identified from January 1992 until January 1994, and female cases until December 1994. Cases were identified through a special organisation set up at the coronary or intensive care units of the 10 emergency hospitals in the region (97\% of all non-fatal cases), and from Sweden's computerised hospital discharge register. Cases were included at time of disease onset and diagnosed according to standard criteria. At the time of an incident case, referents were identified through the computerised population register maintained by Stockholm County. For each case at least one referent was randomly selected from the study base, after stratification for sex, age, and hospital catchment area. Exposure information was obtained from a detailed self administered questionnaire and a health examination. Missing data in any record were filled in by means of a telephone interview. Response rates to the questionnaire were $84.4 \%$ among cases and $73.4 \%$ among referents.
This study was restricted to non-fatal cases $(73 \%$ of all cases) so as to increase the validity of life event information. The study population consists of 1381 non-fatal cases, 968 men and 413 women, and 1697 referents, 1148 men and 549 women. Table 1 shows the characteristics of the study population. A detailed description of the SHEEP study has already been published. ${ }^{45}$

\section{The case-crossover study}

The onset study is a case-crossover study nested in the SHEEP. Each patient serves as his or her own control when crossing back and forth between periods of exposure and non-exposure. Three types of information are required for a study of this kind: time of disease onset, whether the trigger was present during a defined period immediately before onset, and earlier history of exposure to the trigger. The length of the period immediately before disease onset, during which the trigger is considered to have an effect, is chosen by the investigator on the basis of a hypothesised maximum induction time. Whether the case is exposed to the trigger or not during this period determines the "case information". We applied the "matched pair interval approach", in which "control information" consists of exposure during an earlier control period of the same length, which is then individually matched to the case information. This approach is similar to that used in a one to one matched case-control study ${ }^{46}$ Cases for the onset study were identified, for the period April 1993 to December 1994, in the coronary care units of departments 
of internal medicine in Stockholm County. About 70\% of eligible non-fatal cases in the SHEEP study base were included. Specially trained nurses interviewed the 699 cases during their hospital stay or shortly after discharge. Disease onset was defined as the start of diagnostic chest pain. After exclusion of patients with unreliable information on time of onset, or with a high percentage of missing or clearly inaccurate responses, 660 cases remained (507 men and 153 women). Both men and women were recruited throughout the study period. Table 1 shows characteristics of the study population. A detailed description of the onset study has been published elsewhere. ${ }^{2}$

\section{Exposures}

The SHEEP questionnaire contained 14 items on the occurrence of specific life events during the past 12 months ( see appendix 1). Five of these life events were work related. Each life event item was accompanied by an additional question regarding the subjective significance of the event. For "conflicts at work" and "impaired economic situation" the significance were measured on a three point scale (as shown in table 2). The significance of the other events was measured on a five point scale ranging from "affected me in a very negative way" to "affected me in a very positive way" but in the analyses grouped into three categories (as shown in table 2). The scale was developed within the confines of a previous epidemiological study, ${ }^{47}$ and constructed on the basis of previous investigations. ${ }^{32}$ Accumulated life event experience over the past year was defined in two wayseither as the number of events over the past 12 months, or through weighted accumulation according to the SRRS, ${ }^{27}$ with each of the 14 events being given a specific weight. For example, death of spouse gives 100 points and change of residence 20 points. The sums of these weighted values were stratified into quartiles, and the lowest quartile was used to define the reference group. In SHEEP the mean value was 53 for men and 51 for women, and maximum 476 respectively 433 points. The onset interview covered 27 different life event questions of which 13 were considered to be work related (see appendix 2). Fifty five cases did not answer any of the life event questions and were excluded from the analysis. Hypertension, physical inactivity, diabetes, overweight, smoking, and socioeconomic statuses, which were used for the adjusted analyses, were assessed using information from the SHEEP questionnaire and the health examination. Definitions of the standard risk factors are given in the lower part of table 1.

\section{Statistical analyses}

Case-control analysis

The case-control study was analysed using logistic regression. All analyses included adjustments for age and catchments area, and were stratified by sex. Further adjustments were performed for standard risk factors for myocardial infarction. Results are given as odds ratios (OR) with $95 \%$ confidence intervals (CI).

\section{Case-crossover analysis}

The matched pair interval approach of the case-crossover design was analysed using conditional logistic regression. ${ }^{48}$ Exposure during the period before disease onset was compared with exposure during the control period. We report the risk during the day (0-24 hours) before onset compared with the preceding day (25-48 hours). For the analysis of the induction time information from the two weeks before onset was used, comparing exposure during day 2 to day 7 (25 to 168 hours) before onset with the corresponding period the week before that, day 9 to day 14 (193 to 336 hours) before onset. Results are given as odds ratios with $95 \%$ confidence intervals estimating incidence rate ratios. This can be interpreted as the probability for onset of myocardial infarction shortly after exposure to a stressful life event relative to a period of non-exposure. The choice of the conditional logistic regression was made at the beginning of the study as it provides an easy way to control for simultaneous triggers. ${ }^{48}$ However, it turned out that exposure to several events during these short periods was uncommon and the material was not large enough to perform such co-exposure analyses. Using the Mantel-Haenszel estimation ${ }^{49}$ instead of conditional logistic regression results in changed point estimates in the range of 0.1 to 0.3 downwards (only one exposure showed a larger change in point estimate that was "event where felt pressure of competition" that changed from 6.0 (1.3 to 26.8$)$ to $4.5(1.0$ to 20.8$))$. Given theses small

Table 2 Risk of myocardial infarction after exposure to work related life events during the past 12 months, stratified according to self perceived affect of the event. A case-referent analysis. The reference group consists of subjects who did not experience the specific life event. Odds ratios (95\% confidence intervals)

\begin{tabular}{|c|c|c|c|c|}
\hline \multirow[b]{2}{*}{ Events } & \multicolumn{2}{|l|}{ Men } & \multicolumn{2}{|l|}{ Women } \\
\hline & Crude* & Adjusted $†$ & Crude* & Adjustedt \\
\hline Impaired economic situation & $1.0(0.8$ to 1.2$)$ & $0.8(0.6$ to 1.0$)$ & $0.9(0.7$ to 1.3$)$ & $0.7(0.5$ to 1.0$)$ \\
\hline Affected me strongly & $1.7(1.2$ to 2.4$)$ & $1.3(0.9$ to 1.9$)$ & $3.6(1.8$ to 7.2$)$ & 3.0 (1.3 to 6.7$)$ \\
\hline Was noticeable & $1.0(0.8$ to 1.3$)$ & $0.8(0.6$ to 1.0$)$ & $0.7(0.5$ to 1.1$)$ & $0.6(0.4$ to 0.9$)$ \\
\hline Did not mean particularly much & $0.5(0.3$ to 0.7$)$ & $0.4(0.2$ to 0.7$)$ & $0.6(0.3$ to 1.1$)$ & $0.5(0.2$ to 1.0$)$ \\
\hline Conflict at work & $1.7(1.3$ to 2.2$)$ & $1.8(1.4$ to 2.3$)$ & $1.5(1.0$ to 2.4$)$ & $1.6(1.0$ to 2.5$)$ \\
\hline Affected me strongly & $1.8(1.2$ to 2.6$)$ & $2.0(1.3$ to 2.9$)$ & $1.7(0.9$ to 3.2$)$ & $1.8(0.9$ to 3.5$)$ \\
\hline Was noticeable & $2.0(1.4$ to 2.8$)$ & $2.0(1.4$ to 2.9$)$ & $1.3(0.7$ to 2.3$)$ & $1.4(0.7$ to 2.6$)$ \\
\hline Did not mean particularly much & $1.0(0.6$ to 1.7$)$ & $1.0(0.6$ to 1.8$)$ & $2.0(0.6$ to 6.4$)$ & $1.6(0.5$ to 5.8$)$ \\
\hline Change of workplace & $0.9(0.7$ to 1.2$)$ & $1.0(0.7$ to 1.3$)$ & $1.2(0.7$ to 2.2$)$ & $1.2(0.6$ to 2.3$)$ \\
\hline Affected me in a very or fairly negative way & $1.0(0.7$ to 1.7$)$ & $1.1(0.7$ to 1.8$)$ & $2.6(1.0$ to 6.6$)$ & $2.5(0.9$ to 6.9$)$ \\
\hline Did not mean particularly much & $0.9(0.5$ to 1.7$)$ & $0.9(0.5$ to 1.6$)$ & $1.2(0.2$ to 9.0$)$ & $2.1(0.2$ to 17.2$)$ \\
\hline Affected me in a very or fairly positive way & $0.8(0.5$ to 1.2$)$ & $0.9(0.5$ to 1.4$)$ & $0.6(0.2$ to 1.4$)$ & $0.5(0.2$ to 1.4$)$ \\
\hline Decreased responsibilities at work & $1.1(0.8$ to 1.4$)$ & $1.1(0.8$ to 1.6$)$ & $0.5(0.2$ to 1.1$)$ & $0.5(0.2$ to 1.2$)$ \\
\hline Affected me in a very or fairly negative way & $1.1(0.7$ to 1.7$)$ & $1.2(0.8$ to 1.8$)$ & $0.7(0.2$ to 2.5$)$ & $0.4(0.1$ to 1.5$)$ \\
\hline Did not mean particularly much & $1.0(0.5$ to 1.7$)$ & $1.0(0.5$ to 1.8$)$ & $0.9(0.2$ to 3.2$)$ & $1.0(0.2$ to 4.7$)$ \\
\hline Affected me in a very or fairly positive way & $1.1(0.6$ to 1.8$)$ & $1.2(0.7$ to 2.2$)$ & $0.2(0.05$ to 1.1$)$ & $0.4(0.1$ to 2.1$)$ \\
\hline Increased responsibilities at work & $1.1(0.8$ to 1.3$)$ & $1.1(0.9$ to 1.5$)$ & $1.0(0.7$ to 1.6$)$ & $1.2(0.8$ to 2.0$)$ \\
\hline Affected me in a very or fairly negative way & $5.6(2.5$ to 12.9$)$ & $6.3(2.7$ to 14.7$)$ & $3.2(1.2$ to 8.4$)$ & $3.8(1.3$ to 11.0$)$ \\
\hline Did not mean particularly much & $1.5(0.9$ to 2.3$)$ & $1.5(0.9$ to 2.4$)$ & $0.7(0.2$ to 1.9$)$ & $0.8(0.3$ to 2.5$)$ \\
\hline Affected me in a very or fairly positive way & $0.7(0.5$ to 0.9$)$ & $0.8(0.5$ to 1.0$)$ & $0.8(0.5$ to 1.4$)$ & $1.0(0.6$ to 1.8$)$ \\
\hline
\end{tabular}


Table 3 Risk of myocardial infarction after exposure to work related life events, testing induction periods of either one day or one week. A case-crossover analysis. Odds ratios (95\% confidence intervals)

\begin{tabular}{|c|c|c|c|c|}
\hline Events & $\begin{array}{l}\text { Number of } \\
\text { exposed cases } \\
\text { (day 1) }\end{array}$ & Day $1 v$ day $2^{*}$ & $\begin{array}{l}\text { Number of exposed } \\
\text { cases (day } 2 \text { to } \\
\text { day } 7 \text { ) }\end{array}$ & $\begin{array}{l}\text { Day } 2 \text { to } 7 v 9 \text { to } \\
14 \dagger\end{array}$ \\
\hline $\begin{array}{l}\text { Had a high pressure } \\
\text { deadline at work }\end{array}$ & 18 & 6.0 (1.8 to 20.3$)$ & 23 & $1.4(0.7$ to 2.5$)$ \\
\hline $\begin{array}{l}\text { Event where felt pressure } \\
\text { of competition }\end{array}$ & 9 & $2.0(0.6$ to 6.6$)$ & 13 & $6.0(1.3$ to 26.8$)$ \\
\hline $\begin{array}{l}\text { Had major changes in job } \\
\text { tasks or responsibilities }\end{array}$ & 0 & - & 1 & $1.0(0.6$ to 16.0$)$ \\
\hline Praised by the boss & 8 & $2.6(0.7$ to 10.0$)$ & 30 & $2.8(1.4$ to 5.8$)$ \\
\hline Criticised by the boss & 2 & - & 1 & - \\
\hline Promoted or given a raise & 0 & - & 2 & $1.0(0.1$ to 7.1$)$ \\
\hline Quit job or was laid off & 1 & - & 1 & $1.0(0.6$ to 16.0$)$ \\
\hline $\begin{array}{l}\text { Shared positive event } \\
\text { with coworkers }\end{array}$ & 4 & $4.0(0.4$ to 35.8$)$ & 6 & $2.0(0.5$ to 8.0$)$ \\
\hline $\begin{array}{l}\text { Shared negative event } \\
\text { with coworkers }\end{array}$ & 2 & $0.7(0.1$ to 4.0$)$ & 5 & - \\
\hline $\begin{array}{l}\text { Went on business trip or } \\
\text { vacation }\end{array}$ & 0 & - & 12 & $1.2(0.5$ to 3.2$)$ \\
\hline $\begin{array}{l}\text { Experienced a positive } \\
\text { event with regard to } \\
\text { personal finances }\end{array}$ & 0 & - & 3 & $1.5(0.3$ to 9.0$)$ \\
\hline $\begin{array}{l}\text { Experienced a negative } \\
\text { event with regard to } \\
\text { personal finances }\end{array}$ & 3 & $3.0(0.3$ to 28.7$)$ & 2 & - \\
\hline
\end{tabular}

differences and that it does not change our conclusions we have chosen to present the results from the original analytical strategy.

All calculations were made using the SAS software package (version 8.01).

\section{RESULTS}

\section{Single life events - the case-control analyses}

Table 2 shows the risk of myocardial infarction after exposure to work related life events during the past 12 months. Results are derived from the case-control analysis, for which information on the precise timing of the events was not available. Among men "conflict at work" was found to be associated with increased risk, with an adjusted OR of 1.8 (1.4 to 2.3).
The risk was further increased if the event was described as "affecting me strongly". For women the point estimate was also increased, although with a wider confidence interval. "Impaired economic situation" was inversely associated with myocardial infarction among men. When the event "did not mean particularly much" the OR was 0.4 (0.3 to 0.7). Among women the increase in risk was substantial when the impairing economic event was described as "affecting me strongly", OR=3.0 (1.3 to 6.7). Retirement might be considered an economic impairment of lesser importance, and also foreseeable, but the associations remained after further adjustment for retirement during the past 12 months. For both men and women there was an increased risk associated with "increased responsibilities at

Table 4 Risk of myocardial infarction after accumulated experience of life events during the past 12 months, measured as the total number of events. Case-referent analysis where the patients with no events at all constituted the reference group. Odds ratios $195 \%$ confidence intervals)

\begin{tabular}{|c|c|c|c|c|}
\hline \multirow{3}{*}{$\begin{array}{l}\text { Number of life } \\
\text { events ( } 14 \\
\text { possible) }\end{array}$} & \multicolumn{2}{|l|}{ Men } & \multicolumn{2}{|l|}{ Women } \\
\hline & \multirow{2}{*}{$\begin{array}{l}\text { Crude* }^{*} \\
966 \text { cases, } \\
1147 \text { referents }\end{array}$} & \multirow{2}{*}{$\begin{array}{l}\text { Adjustedt } \\
937 \text { cases, } \\
1126 \text { referents }\end{array}$} & \multirow{2}{*}{$\begin{array}{l}\text { Crude* }^{*} \\
411 \text { cases, } \\
549 \text { referents }\end{array}$} & \multirow{2}{*}{$\begin{array}{l}\text { Adjusted } t \\
370 \text { cases, } \\
509 \text { referents }\end{array}$} \\
\hline & & & & \\
\hline 0 & 1.0 & 1.0 & 1.0 & 1.0 \\
\hline 1 & $0.9(0.7$ to 1.2$)$ & $0.9(0.7$ to 1.1$)$ & $0.9(0.6$ to 1.2$)$ & $0.7(0.4$ to 1.0$)$ \\
\hline 2 & 0.9 (0.7 to 1.2$)$ & $0.9(0.6$ to 1.1$)$ & $1.0(0.7$ to 1.6$)$ & $1.0(0.6$ to 1.5$)$ \\
\hline 3 & $1.0(0.7$ to 1.4$)$ & $1.1(0.8$ to 1.5$)$ & $1.1(0.7$ to 1.8$)$ & $0.9(0.5$ to 1.5$)$ \\
\hline 4 & $1.0(0.6$ to 1.4$)$ & $1.0(0.7$ to 1.6$)$ & $1.9(1.1$ to 3.4$)$ & $1.4(0.7$ to 2.7$)$ \\
\hline 5 & $1.1(0.8$ to 1.9$)$ & $1.0(0.6$ to 1.7$)$ & $0.7(0.3$ to 1.9$)$ & $0.4(0.1$ to 1.2$)$ \\
\hline 6 & $1.0(0.5$ to 1.9$)$ & $1.0(0.5$ to 2.0$)$ & 1.9 (0.5 to 7.3$)$ & $1.7(0.4$ to 7.6$)$ \\
\hline 7 & $1.5(0.3$ to 6.8$)$ & $2.4(0.4$ to 15.0$)$ & $1.5(0.2$ to 11.6$)$ & $0.9(0.1$ to 8.4$)$ \\
\hline 8 & $2.3(0.2$ to 25.6$)$ & $0.8(0.05$ to 14.2$)$ & - & - \\
\hline 9 & $0.6(0.05$ to 6.3$)$ & $0.3(0.03$ to 3.9$)$ & - & - \\
\hline $\mathrm{p}$ for trend $\ddagger$ & 0.6121 & 0.8116 & 0.1312 & 0.7148 \\
\hline
\end{tabular}

*Crude, analysis controlled for age and hospital catchment area. †Adjusted, analysis controlled for age, hospital catchment area, hypertension, physical inactivity, diabetes, overweight (BMI $\geqslant 27$ ), smoking, and socioeconomic status. -, Analysis not possible. $\neq \mathrm{p}$ for trend based on $\chi^{2}$ test for trend. 
work" when these were considered very or fairly negativefor men $\mathrm{OR}=6.3$ (2.7 to 14.7 ), and for women $\mathrm{OR}=3.8(1.3$ to 11.1 ).

\section{Single events - the case-crossover analyses}

In the case-crossover analysis about $8 \%$ of the interviewed patients had experienced a work related life event the day before their infarction. The corresponding proportion for non-work related events was much lower. Only two patients had, for instance, experienced "death of a friend, relative or significant person". Table 3 shows the trigger risk of myocardial infarction after experiencing a work related event. Using a one day hazard period, we found a statistical significant increased risk for the event "had a high pressure deadline", OR $=6.0$ ( 1.8 to 20.3). The point in time for "had a high pressure deadline" relates to the timing of the deadline itself and not to the time for which the deadline was announced and/or set. Some other events had increased risk estimates, for example "praised by the boss" OR $=2.6$ ( 0.7 to 10.0), and "felt pressure of competition" $\mathrm{OR}=2.0$ (0.6 to 6.6). For six of the events it was not possible calculate a risk estimate, mainly because there was no such events in the period immediately before onset. However, for "criticised by the boss" and "quit or was laid off" there were exposed cases during the day before onset but not in the control period. None of the patients had experienced the event described as having "fired or disciplined someone". Statistical power was insufficient to permit analyses of effect modification, but the point estimates for men and women were quite similar.

It might be expected intuitively that positive feedback from the boss usually is related to a successful work effort. Accordingly the most common combination of co-exposure of work related life events was "praised by the boss" and "had a high pressure deadline". Eleven of the 39 cases who were "praised by the boss" during the two week period before onset were also exposed to a "high pressure deadline" within the same time period. In all these cases the praise event came after the high pressure deadline. Some of the increased risk associated with praise might therefore be confounded by the preceding deadline. After controlling for such co-exposure-by excluding the co-exposed cases in the analysis of "praised by the

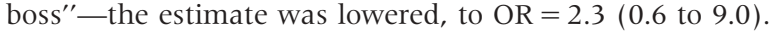

The induction time analysis was restricted to comparing two longer hazard periods before onset, excluding the cases considered as exposed in the first analysis (those exposed within one day before onset). This analysis showed increased risk estimates for "praised by the boss" and "felt pressure of competition" whereas the other events showed small or no increases in risk. The material was not large enough for a more detailed analysis of the length of the induction periods.
The conclusion is that there might be events for which the induction period exceeds 24 hours, but for most of the events it seems not.

\section{Accumulation of stressful life events - the case-control analysis}

Accumulation of stressful life events, measured as the total number of events during the past 12 months, showed no significantly increased risk (table 4 ). The only significantly increased risk was found for women with four events, giving —in the crude analysis-an OR of 1.9 ( 1.1 to 3.4). This finding did not remain statistical significant after adjustment for standard myocardial infarction risk factors. Treating the exposure as a continuous variable in the analyses also did not result in any increased risk estimates (for men crude OR 1.02 (0.98 to 1.08) and adjusted OR of 1.00 (0.95 to 1.06) and for women 1.05 (0.97 to 1.13 ) respectively 1.00 (0.90 to 1.01$)$. Nor did accumulation of events weighted by their significance according to the SRRS result in significantly increased risks among participants with higher scores (table 5).

\section{DISCUSSION}

In this case-crossover study we found that life events experienced in working life, and characterised by high demands, competition, or conflict, are potential triggers of the onset of myocardial infarction. Although it was not possible fully to explore the length of the induction period in the study, the results suggest that the induction time is in the range of hours or days rather than weeks. Analysis of specific life events in the case-control study supports the view that some work related events may increase the risk of myocardial infarction, especially if such events have a strong subjective significance. We had no information for the case-control study on when the events occurred during the 12 month period. Therefore, it was not possible to identify how much of the effect was driven by life events occurring close in time to the outcome-that is, by a trigger mechanism. Analyses of the two different measures of accumulation do not support the hypothesis that the mechanisms involved in excess risk of myocardial infarction is related to the number of life events experienced over a period of 12 months.

Only a few earlier studies have paid special attention to the time relation between life events and the onset of myocardial infarction. In 1976 Connolly et al reported significantly more life events among cases of infarction over a three week period before onset. ${ }^{35}$ In 1993 another case-control study showed significantly increased risks associated with emotionally upsetting events within 24 hours of onset (adjusted OR $=$ 2.7 (1.1 to 6.6)), and emotional stress at work within four weeks of onset (adjusted OR $=1.4(1.0$ to 2.1$)){ }^{3}$ So far the

Table 5 Risk of myocardial infarction after accumulated experience of life events during the past 12 months, measured and summed according to SRRS weighting. Stratified in quartiles. Case-referent analysis where the lowest quartile was used as reference group. Odds ratios (95\% confidence intervals)

\begin{tabular}{|c|c|c|c|c|}
\hline \multirow[b]{3}{*}{$\begin{array}{l}\text { Number of SRRS } \\
\text { points }\end{array}$} & \multicolumn{2}{|l|}{ Men } & \multicolumn{2}{|l|}{ Women } \\
\hline & Crude* & Adjustedt & Crude* & Adjustedt \\
\hline & $\begin{array}{l}921 \text { cases, } \\
1096 \text { referents }\end{array}$ & $\begin{array}{l}896 \text { cases, } \\
1077 \text { referents }\end{array}$ & $\begin{array}{l}389 \text { cases, } \\
515 \text { referents }\end{array}$ & $\begin{array}{l}350 \text { cases, } \\
482 \text { referents }\end{array}$ \\
\hline 0 & 1.0 & 1.0 & 1.0 & 1.0 \\
\hline $1-36$ & $0.9(0.7$ to 1.2$)$ & 0.9 (0.6 to 1.1$)$ & $0.8(0.5$ to 1.3$)$ & $0.6(0.4$ to 1.0$)$ \\
\hline $37-78$ & $1.0(0.8$ to 1.2$)$ & $1.0(0.7$ to 1.2$)$ & $0.9(0.7$ to 1.3$)$ & $0.8(0.6$ to 1.3$)$ \\
\hline$\geqslant 79$ & $1.0(0.8$ to 1.2$)$ & $1.0(0.7$ to 1.3$)$ & $1.3(0.9$ to 1.9$)$ & $1.0(0.6$ to 1.5$)$ \\
\hline $\mathrm{p}$ for trend $\ddagger$ & 0.9552 & 0.7122 & 0.1706 & 0.6820 \\
\hline
\end{tabular}

*Crude, analysis controlled for age and hospital catchment area. †Adjusted, analysis controlled for age, hospital catchment area, hypertension, physical inactivity, diabetes, overweight (BMI $\geqslant 27)$, smoking, and socioeconomic status. $\neq p$ for trend based on $\chi^{2}$ test for trend. 
only published case-crossover study of the relation between life events and myocardial infarction has been performed by Mittleman et al. ${ }^{10}$ They reported the risk of onset of myocardial infarction within one day after experiencing "death of a significant person" to increase 14 times. ${ }^{10}$ Several studies have also concluded that work related life events are particularly prone to increase the risk of myocardial infarction. ${ }^{33} 3844$ A prospective study of the association between problems and life events over a 12 month period and the risk of developing a myocardial infarction in the subsequent year showed a significantly increased risk $(\mathrm{OR}=1.64$ ( $\mathrm{p}$ value $<0.01)$ ) with exposure to any work load factor and subsequent risk. ${ }^{38}$

\section{Limitations of the study}

In case-crossover analyses, there is a problem of recall bias if subjects report events during the case period and the control period with differential recall. However, in this case, as neither the interviewers nor the patients were informed about length of hypothetical induction periods, they could not distinguish between the case and the control period. A gradual loss of recall when thinking back over two weeks or two days would, however, still lead to an overestimation of the risk. Comparing two periods excluding the effect period, for example day 7 with day 14, resulted in risk estimates of about 1, for "had a high pressure deadline" OR $=1.1$ (95\% CI 0.5 to 2.2 ), which supports that although there might be a problem with misclassification it is does not seem to differentiate between a period closer to onset than for a period further back in time. In addition, information from the onset interview shows that recall bias also might not be a major problem. Each onset interview was started by asking the patient what he or she thought had caused or started their infarction, and the same question was repeated at the very end of interview. Few patients had the preconceived idea that a life event had caused or started their infarction, and those who thought so kept this view towards the end of the interview during which several potential areas had been covered. Among the 117 patients who had experienced a work related event during the week before their myocardial infarction (the exposed cases), 47 had an idea of some kind about what had prompted their infarction. Seven patients thought it was an event (not necessarily a work related event) and, from among these, four thought it was an event occurring within the past three weeks. After the interview six of them still held the same opinion. Furthermore, the finding of increased risk only for some specific life events, and not for all, argues against the importance of recall bias in both the case-control and the case-crossover analyses.

In a case-crossover study all comparisons are made within the same person. Accordingly, neither the confounding effects of long term risk factors nor the selection of controls is a potential source of bias. However, confounding attributable to exposure to other triggers during the period before disease onset might arise. In our study concurrent trigger exposure was found to be unusual. Excluding cases that were exposed to other known triggers, physical exertion, anger, and sexual activity only slightly reduced risk estimates for work related life events.

In the case-control analysis we controlled for age and hospital catchment area, and further for standard myocardial infarction risk factors, such as hypertension, physical inactivity, diabetes, overweight, smoking, and socioeconomic status. The increased risk estimates were only slightly affected by adjustment for the confounders. The increased risk for "impaired economic situation" remained after further adjustment for retirement, and the increased risks for work related events also remained after adjustment for measures of hostility, type A behaviour, and covert coping.
Only first events of non-fatal myocardial infarction were included in this study. It seems unlikely that recent exposure to life events would influence the prognosis of myocardial infarction. The results may therefore be generalised to fatal myocardial infarction, provided that the mechanism through which life events increase the risk of myocardial infarction is basically similar for both fatal and non-fatal cases.

In previous case-crossover analyses we found it necessary to distinguish between patients with and without premonitory symptoms. This was because of the risk of misclassification of case exposure and the risk of reversed causation among cases with premonitory symptoms. Most events covered by this analysis are impossible or difficult to prevent or avoid, and it is therefore unlikely that premonitory symptoms would influence the probability of experiencing such events.

Our conclusion is that work related life events characterised by high demands, competition, or conflict have the potential to trigger the onset of myocardial infarction. This is the first study to show this, and the result is therefore in need of confirmation. However, from what is known about other triggers of myocardial infarction and presumed mechanisms, such as haemodynamic changes and plaque rupture leading to thrombosis, the result has a high degree of biological plausibility. It should be noted that the case-crossover analyses could not distinguish between early or excess cases. ${ }^{50}$ Whether a triggered case actually is an excess case over a longer period needs still to be established. To understand the potential public health importance of a sixfold increase in relative risk over a short time period, it is helpful to estimate the increase in risk on an annual basis. For example, the SHEEP study showed that a 55-70 year old man in the Stockholm area had a yearly risk of $0.464 \%$ of myocardial infarction. If he worked eight hours per day, five days a week, and experienced pressing time restrictions once a week, (20\% of working time), his yearly risk would increase to $0.564 \%$, giving an annual risk ratio of 1.215 . This estimate of $20 \%$ excess risk is conservative, as the effect of the trigger was assumed to last over just one and the same working day.

\section{Authors' affiliations}

J Möller, J Hallqvist, Department of Public Health Sciences, Division of Social Medicine, Karolinska Institutet, Stockholm, Sweden

T Theorell, Swedish National Institute for Psychosocial Factors and Health, Stockholm, Sweden

$\mathrm{U}$ de Faire, Institute of Environmental Medicine, Division of Cardiovascular Epidemiology, Karolinska Institutet

A Ahlbom, Institute of Environmental Medicine, Division of Epidemiology, Karolinska Institutet

Funding: the study was supported by grants from the Swedish Council for Social Research, Sweden's National Institute of Public Health, and the Swedish Council for Working Life and Social Research.

Conflicts of interest: none declared.

The ethics committee of Karolinska Institutet approved both the SHEEP study and the embedded onset study.

\section{APPENDIX 1}

LIST OF THE LIFE EVENT ITEMS IN THE QUESTIONNAIRE USED FOR THE CASE-REFERENT STUDY (SHEEP).

Have you experienced any of the following life events during the past 12 months? (yes/no)

- Conflict with wife/husband/cohabitant.

- Conflict with close relative or close friend.

- Illness/accident to wife/husband//cohabitant.

- Death of wife/husband/cohabitant. 
- Death of close relative or close friend.

- Impaired economic situation.

- Conflict at work.

- Dissolution of marriage (or equivalent).

- Got married or started cohabiting.

- Moved home.

- Had a child or adopted a child.

- Change of workplace.

- Decreased responsibilities at work.

- Increased responsibilities at work.

\section{APPENDIX 2}

\section{LIST OF THE LIFE EVENT QUESTIONS POSED IN THE INTERVIEW FOR THE CASE-CROSSOVER (ONSET) STUDY}

\section{During the past year ... (yes/no)}

- Did your boss (or superior) praise you for a job well done?

- Did your boss criticise you for your performance, lateness, etc?

- Were you told you were promoted or given a raise?

- Did you quit or were you laid off?

- Did you have a major change in job tasks or responsibilities?

- Did you fire or discipline someone at work?

- Did you have a high pressure deadline at work?

- Did you share a very positive event with coworkers, involving feelings of joy or an emotional high?

- Did you experience a very negative event with coworkers, involving feelings of aggravation, anxiety or grief?

- Did you have a business trip or vacation out of town?

- Were you involved in an event when you felt the pressure of competition?

- Did you experience a very positive event in your personal finances?

- Did you experience a very negative event in your personal finances?

- Any "Yes" response to a life event question was followed by two further questions:

- When did this last happen before your infarction?

- When did it last happen before that?

\section{REFERENCES}

1 Mittleman MA, Maclure M, Tofler GH, et al. Triggering of acute myocardial infarction by heavy physical exertion. Protection against triggering by regular exertion. Determinants of Myocardial Infarction Onset Study Investigators. N Engl J Med 1993;329:1677-83.

2 Hallqvist J, Moller J, Ahlbom A, et al. Does heavy physical exertion trigger myocardial infarction? A case-crossover analysis nested in a populationbased case-referent study. Am J Epidemiol 2000;151:459-67.

3 Willich SN, Lewis $M$, Lowel $H$, et al. Physical exertion as a trigger of acute myocardial infarction. Triggers and Mechanisms of Myocardial Infarction Study Group. N Engl J Med 1993;329:1684-90.

4 Mittleman MA, Maclure M, Sherwood JB, et al. Triggering of acute myocardial infarction onset by episodes of anger. Determinants of Myocardial Infarction Onset Study Investigators. Circulation 1995;92:1720-5.

5 Moller J, Hallqvist J, Diderichsen F, et al. Do episodes of anger trigger myocardial infarction? A case-crossover analysis in the Stockholm heart epidemiology program (SHEEP). PsychosomMed, 1999;61:842-9.

6 Muller JE, Mittleman A, Maclure M, et al. Triggering myocardial infarction by sexual activity. Low absolute risk and prevention by regular physical exertion. Determinants of Myocardial Infarction Onset Study Investigators. JAMA 1996;275:1405-9.

7 Moller J, Ahlbom A, Hulting J, et al. Sexual activity as a trigger of myocardial infarction. A case-crossover analysis in the Stockholm heart epidemiology programme (SHEEP). Heart 2001;86:387-90.

8 Mittleman MA, Mintzer D, Maclure M, et al. Triggering of myocardial infarction by cocaine. Circulation 1999;99:2737-41.
9 Mittleman MA, Lewis RA, Maclure $M$, et al. Triggering myocardial infarction by marijuana. Circulation 2001;103:2805-9.

10 Mittleman MA, Maclure MA, Sherwood JB, et al. Death of a significant person increases the risk of acute Ml onset. [Abstract]. Circulation 1996;93:621.

11 Muller JE, Tofler GH, Stone PH. Circadian variation and triggers of cardiovascular disease. Circulation 1989:4:733-43.

12 Muller JE, Abdela GS, Nesto RW, et al. Triggers, acute risk factors and vulnerable plaques: the lexicon of a new frontier. J Am Coll Cardiol 1994:23:809-13.

13 Gullette ECD, Blumenthal JA, Babyak $M$, et al. Effects of mental stress on myocardial ischemia during daily life. JAMA 1997;277:1521-6.

14 Tofler GH, Stone PH, Maclure M, et al. Analysis of possible triggers of acute myocardial infarction (The MILIS study). Am J Cardiol 1990;66:22-7.

15 Willich SN, Löwel $\mathrm{H}$, Lewis $M$, et al. Association of wake time and the onset of myocardial infarction: triggers and mechanisms of myocardial infarction (TRIMM) pilot study. Circulation 1991;84(suppl 6):VI62-7.

16 Behar S, Halabi $M$, Reicher-Reiss $H$, et al. Circadian variation and possible external triggers of onset of myocardial infarction. Am J Med 1993;94:395-400.

17 Gelernt MD, Hochman JS. Acute myocardial infarction triggered by emotional stress. Am J Cardiol 1992;69:1512-13.

18 Sumiyoshi T, Haze K, Saito M, et al. Evaluation of clinical factors involved in onset of myocardial infarction. Jpn Circ J 1986:50:164-73.

19 Barach P, Rivkind A, Israeli A, et al. Emergency preparedness and response in Israel during the Gulf War [corrected and republished article originally printed in Ann Emerg Med 1997;30:513-21]. Ann Emerg Med 1998:32:224-33

20 Mihatov S, Bergovec M, Prpic $\mathrm{H}$, et al. Incidence and hospital mortality of acute coronary artery disease among civilians in Zagreb during air-raid alarms. Acta Med Croatica 1995;49:49-52.

21 Brown DL. Disparate effects of the 1989 Loma Prieta and 1994 Northridge earthquakes on hospital admissions for acute myocardial infarction: importance of superimposition of triggers. Am Heart J 1999;137:830-6.

22 Leor J, Kloner RA. The Northridge earthquake as a trigger for acute myocardial infarction. Am J Cardiol 1996;77:1230-2.

23 Trichopoulos D, Katsouyanni K, Zavitsanos X, et al. Psychological stress and fatal heart attack: the Athens (1981) earthquake natural experiment. Lancet 1983;i:441-4.

24 Suzuki S, Sakamoto S, Miki T, et al. Hanshin-Awaji earthquake and acute myocardial infarction. Lancet 1995;345:981

25 Haroutune KA, Melkonian AK, Hovanesian AP. Long term mortality and morbidity related to degree of damage following the 1988 earthquake in Armenia. Am J Epidemiol 1998;148:1077-84.

26 Aronsson G. Influence of worklife on public health. Scand J Work Environ Health 1999;25:597-604.

27 Holmes TH, Rahe RH. The social readjustment rating scale. J Psychosom Res 1967;11:213-18.

28 Rahe RH. Life changes, stress responsivity, and captivity research. Psychosom Med 1990;52:373-96.

29 Miller MA Rahe RH. Life changed scaling for the 1990s. J Psychosom Res 1997;43:279-92.

30 Brown GW, Sklair F, Harris TO, et al. Life events and psychiatric disorders. 1. Some methodological issues. Psychol Med 1973;3:74-87.

31 Paykel ES. Life stress depression and attempted suicide. J Hum Stress 1976;2:3-12

32 Dohrenwend BS, Dohrenwend BP, eds. Stressful life events, their nature and effects. New York: Wiley, 1974.

33 Theorell T. Critical life events and cardiovascular disease. In: Cooper CL, ed. Handbook of stress, medicine, and health. Boca Raton, FL: CRC Press, 1996:33.

34 Chorot P, Sandin B. Life events and stress reactivity as predictors of cancer, coronary heart disease and anxiety disorders. Int J Psychosom 1994:41:34-40.

35 Connolly J. Life events before myocardial infarction. J Hum Stress 1976;2:3-17.

36 Magni G, Corfini A, Berto F, et al. Life events and myocardial infarction. Aust N Z J Med 1983;13:257-60.

37 Siegrist J, Dittman K, Rittner K, et al. The social context of active distress in patients with early myocardial infarction. Soc Sci Med 1982;16:443-53.

38 Theorell T, Floderus-Myrhed B. 'Workload' and risk of myocardial infarction-a prospective psychosocial analysis. Int J Epidemiol 1977;6:17-21

39 Welin C. Psychsocial factors in myocardial infarction patients - a case-control study. [Dissertation]. Gothenburg: Gothenburg University, 1995

40 Rosengren A, Tibblin G, Wilhelmsen L. Self-perceived psychological stress and incidence of coronary artery disease in middle-aged men. Am J Cardiol $1991 ; 68: 1171-5$

41 Cottington EM, Matthews KA, Talbott E, et al. Environmental events preceding sudden death in women. Psychosom Med 1980;42:567-74.

42 Shiu LP, Hui WM, Lam SK. Negative social events, stress and health in Hong Kong. J Epidemiol Community Health 1993;47:181-5.

43 Hollis JF, Connett JE, Stevens VJ, et al. Stressful life events, type A behaviour, and the prediction of cardiovascular and total mortality over six years. MRFIT group. J Behav Med 1990;13:263-80.

44 Theorell $\mathrm{T}$, Lind $\mathrm{E}$, Flodérus $\mathrm{B}$. The relationship of disturbing life-changes and emotions to the early development of myocardial infarctions and other serious illnesses. Int J Epidemiol 1975;4:281-93.

45 Reuterwall C, Hallqvist J, Ahlbom A, et al. Higher relative, but lower absolute risks of myocardial infarction in women than in men: analysis of some major risk factors in the SHEEP study. The SHEEP Study Group. J Intern Med 1999;246:161-74 
46 Maclure M Mittleman MA. Should we use a case-crossover design? Ann Rev Public Health 2000;21:193-221.

47 Theorell T, Michélsen H, Nordemar R, et al. Levnadshändelser och copingmönster i Stockholmsundersökningen 1 [Life events and coping patterns in the MUSIC 1 Stockholm study]. In: Hagberg M, Hogstedt C, eds. Solna: MUSIC Books, 1991
48 Maclure M. The case-crossover design: A method for studying transient effects on the risk of acute events. Am J Epidemiol 1991;133:144-53.

49 Vines SK, Farrington CP. Within-subject exposure dependency in casecrossover studies. Stat Med 2001;20:3039-49.

50 Greenland S, Robins JM. Conceptual problems in the definition and interpretation of attributable fractions. Am J Epidemiol 1988;6:1185-97.

\section{THE JECH GALLERY}

\section{Hygiene charter: laying down the spirit of the Healthy City}

$\mathrm{N}$ o one can be responsible for your own health except yourself. In the fight against infectious disease, individuals need to maintain good hygiene for themselves, their families and the community at large. The Hygiene Charter was launched in Hong Kong during the epidemics of SARS as a continuing effort in the fight against the infection. ${ }^{1}$ The charter has put forward suggestions and guidelines on hygiene practices for individuals, management, and business and organisations over 10 sectors. It aims to encourage individuals, as well as business and industry sectors, to pledge their commitment to creating a new culture of hygiene in Hong Kong.

Effective public health practice needs to involve the community at large and encourage people to be involved in all decision making processes relating to health. Up to January 2004 the numbers in each sector who had signed this Hygiene Charter were as follows: personal and family (20 651), education (258), social welfare (199), finance and commercial (54), building (27), medical and health (24), industrial (22), sports and culture (18), catering (14), public transportation (12), tourism (12), and government department (4). ${ }^{2}$

In coping with epidemics of infectious disease, one would consider a healthy epidemic.

The Healthy Cities movement, can provide a framework for an integrated and holistic approach to public health. The Hygiene Charter has facilitated the individual citizen to take positive action, increase individual awareness of health and hygiene, and create a healthy living environment.

\section{ACKNOWLEDGEMENTS}

I would like to acknowledge members of the Steering Committee and Working Group of Operation UNITE for the advice and continuing support.

Albert Lee Centre for Health Education and Health Promotion, The Chinese University of Hong Kong Kai Ming Chan Department of Orthopaedics and Traumatology, The Chinese University of Hong Kong
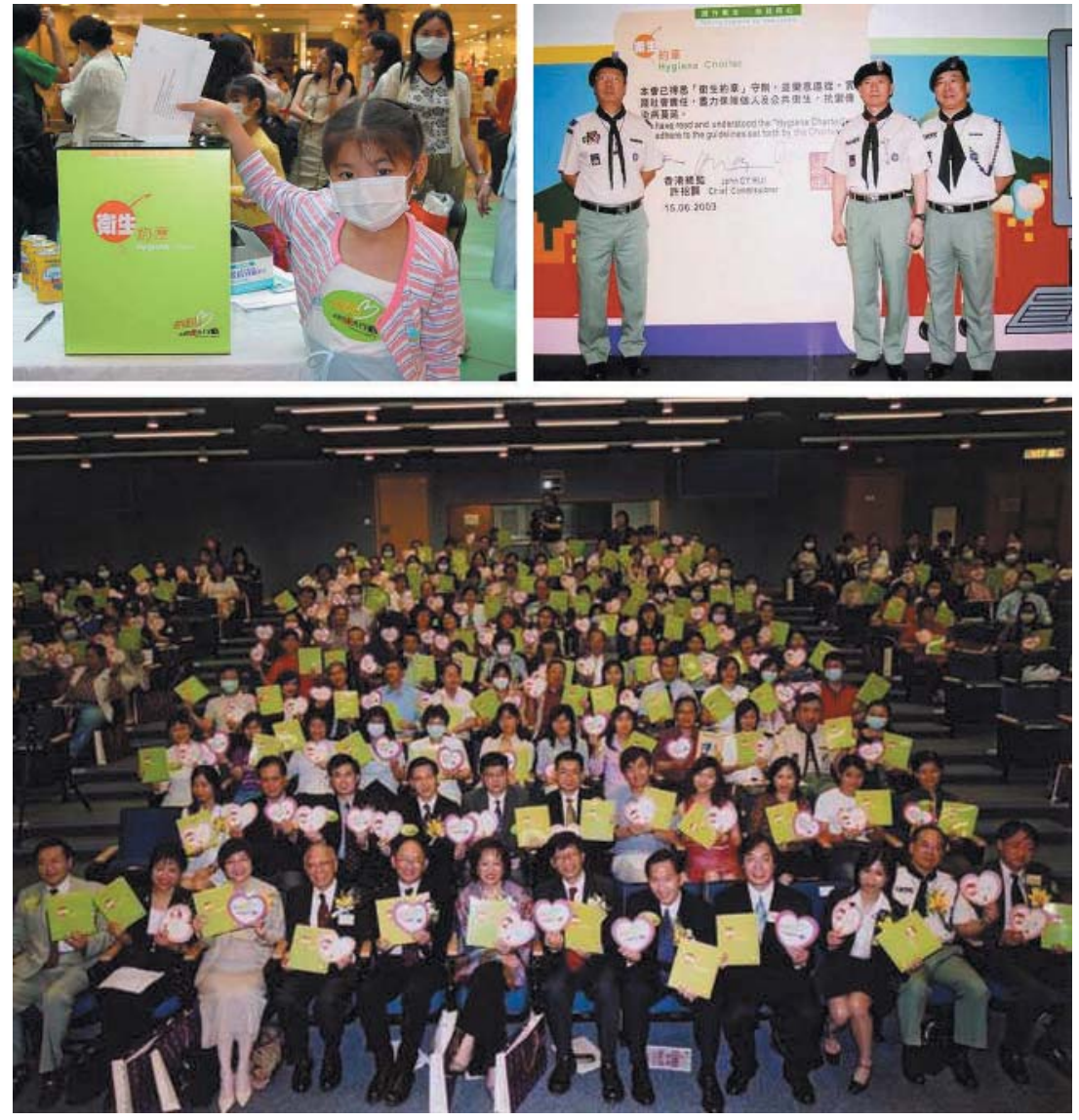

Top left picture: a young school girl pledges her commitment to making Hong Kong clean and health. Top right picture: scout leaders make their commitment. Bottom picture: different sectors make their commitment at the Hygiene Charter Symposium.

Correspondence to: Professor A Lee, Centre for Health Education and Health Promotion, Faculty of Medicine, 4th Floor, School of Public Health, Prince of Wales Hospital Shatin, NT, Hong Kong; alee@cuhk.edu.hk

\section{REFERENCES}

1 Operation UNITE. Hygiene charter: taking hygiene to new levels. Operation UNITE, 2003. http:// www.cuhk.edu.hk/med/hep/hygiene charter/hygiene charter.html.

2 Lee A, Cheng FKK, Yuen HSK, et al. Significance of Hygiene Charter towards different sectors in Hong Kong. Asia Pac J Public Health (in press). 